\title{
«¿QUÉ ES SER UNA MUJER?»: HISTERIA Y POSMODERNIDAD EN A STREETCAR NAMED DESIRE
}

\author{
$\mathrm{M}^{\mathrm{a}}$ SOLEDAD SÁNCHEZ Gómez \\ Universidad Politécnica de Madrid \\ ssanch22@gmail.com
}

\section{REsumen}

Frente al planteamiento de género, dicotómico e invariable, basado en la tradición humanista y destacado por gran parte de la crítica teatral y literaria como algo esencial a la hora de analizar A Streetcar Named Desire, mi intención es demostrar que la obra, de manera compleja y sutil, rompe esta dicotomía por medio de la figura de Blanche, la histérica que desestabiliza el sistema de sexo/género normativo preestablecido por la sociedad patriarcal.

En esta línea, la ya mítica representación realizada por el grupo teatral norteamericano Split Britches en 1991, basada en una relectura libre de esta obra, dinamita otras lecturas anteriores al utilizar la homosexualidad, una hiperfeminidad travestida y el juego de roles queer como clave de interpretación. Tanto Split Britches, con su versión transgénero, como la Blanche más ortodoxamente presentada por Tennessee Williams plantean la eterna pregunta que según Jacques Lacan lanza abierta o subliminalmente toda mujer con una estructura psíquica histérica: "Qué es una mujer?, ¿qué significa serlo?, ¿̨uál es su deseo?".

Palabras Clave: histeria, deseo, teoría queer, Belle Reprieve, Split Britches.

ABSTRACT:

Many critics have tended to assume the traditionally humanist understanding of 
gender as rigid and binary when analysing A Street Car Named Desire. It is the purpose of this essay to demonstrate that this play breaks up this dichotomy in a subtle and complex way through the figure of Blanche, the hysteric able to destabilise the sex/gender system as established by patriarchal society.

In this vein, the already mythical performance of this play by the American theatre group Split Britches, undermines former readings by using homosexuality, cross-dressed hyperfemininity and queer role-playing as keys for interpretation. Both the original (more orthodox) Blanche as portrayed by Tennessee Williams and the Split Britches re-reading of this play present the enduring questions posed time and again by women with a hysterical psychic structure: "What is a woman?, What does it mean? What is her desire?"

KEY WORDs: hysteria, desire, queer theory, Belle Reprieve, Split Britches.

Cuando Blanche Du Bois, fascinante protagonista de A Streetcar Named Desire (1947), obra maestra del dramaturgo estadounidense Tennessee Williams, llega a la calle Campos Elíseos de Nueva Orleans, aturdida y desubicada, arrastra todo un mundo en derrumbe en su maleta. Blanche escapa de una realidad terrible: la enfermedad, la muerte de parientes a los que ha cuidado, la pérdida de la casa familiar (Belle Reve), la falta de trabajo y, como más tarde averiguará el espectador, la huida de la hostilidad que suscita su presunta promiscuidad sexual en Laurel, Mississippi. Además de su catástrofe vital, Blanche nos traslada el innegable final de un mundo con unas costumbres en desuso de las que ella misma es representación. Es el decadente universo sureño que agoniza frente a la emergencia imparable de un mundo industrializado que, a pesar de su fuerza y vitalidad, carece de glamour y que la propia Blanche percibe como lleno vulgaridad y crueldad. Blanche no habita ninguno de los dos mundos y no encuentra su sitio en ninguna de esas fuerzas antagónicas, y ése es precisamente un aspecto clave del drama que vive pues no encontrar un espacio propio, ni siquiera en su deseo, fuerza a la mujer a andar errática dependiendo de esa «kindness of strangers» que Blanche parece encontrar en sus turbias aventuras nocturnas.

Por otro lado, su contrapunto masculino, Stanley Kowalski, es el representante de una masculinidad normativa y de ese mundo de los blue-collar: ruidoso, asertivo, directo, en uso del poder, primitivo, tosco, epítome del disfrute animal ante la vida y convencido de ser «un gallo ricamente emplumado entre las gallinas» ${ }^{1}$. La presentación de este personaje en la primera escena es ya toda una declaración de unos principios de actuación básicos que se opondrán frontalmente a la manera de estar en el mundo de Blanche. No es de extrañar pues que la suspicacia inicial que existe entre ellos pase poco a poco a ser una abierta animosidad y un terrible enfrentamiento; que culminan con la

${ }^{1}$ Todas las citas en español de este artículo se han tomado de la traducción de la obra de Tennessee Williams realizada por Amado Diéguez para la edición de Alba Editorial de 2007. 
violación de Blanche a manos de su cuñado. Una violación que no es de ninguna manera la manifestación de una sexualidad agresiva -como muchos críticos han decidido ver-, sino una muestra de la brutal agresividad que ciertos hombres sienten hacia las mujeres y que se manifiesta de manera sexualizada porque es precisamente a través del sexo como esa violencia encuentra cauce de expresión ${ }^{2}$.

Muchos críticos literarios y teatrales y autores de reseñas han analizado exhaustivamente esta confrontación entre dos mundos y han interpretado a Blanche, con cierta conmiseración, como el elemento más débil de la oposición irreconciliable que existe entre los dos polos del sistema binario sexo/género presente en el mundo occidental, patriarcal y heterosexista desde el Humanismo hasta nuestros días. Influidos e influidas por todos los estereotipos vigentes en torno a las mujeres, estos críticos han visto a Blanche como una víctima paralizada por la soledad, el dolor y la muerte; como una ninfómana insaciable, mentalmente alterada, que produce piedad y rechazo por su voracidad sexual, o como la ingenua que se entrega sin criterio alguno a esa supuesta «amabilidad de los desconocidos $»^{3}$, una lectura que ignora que a veces es precisamente en la contingencia de ese encuentro con quien viene de fuera, donde encontramos ese lugar en el otro que anhelamos, ya que en muchas ocasiones lo siniestro o lo inquietante (das Unheimliche) surge precisamente en el entorno de lo familiar y lo cotidiano, y por eso lo terrible se nos puede hacer tan insoportable. Blanche ha sido para muchos la encarnación de lo femenino, lo poco razonable, «the other», aquello que es expulsado porque incomoda y saca a la luz en nosotros lo que queremos olvidar. A través de su interacción con Blanche vemos a un Mitch cobarde y sometido a su madre; a una Stella dependiente sexualmente e infantilizada, y a un Stanley que aúlla el discurso dominante del patriarcado «con una extrema pobreza sintáctica» (Gibbs 1996: 57) y que pretende seguir ubicado en la «microfísica del poder», algo que, en términos foucaultianos sería el resultado de una multiplicidad de relaciones de fuerza que operan en una esfera determinada. Como sucede con demasiada frecuencia, el pharmakon utilizado para regenerar de manera terapéutica la situación consiste básicamente en expulsar al diferente para así cimentar al resto: Blanche acaba sometiéndose a la autoridad clínica de los psiquiatras (que casualmente son hombres) y es internada en un psiquiátrico, lugar acertadamente analizado por Foucault como uno de los lugares de confinamiento, además de la prisión y el asilo, a través de los que los mecanismos de represión social han ejercido su poder de disciplina y castigo sobre los cuerpos salvajes de los disidentes.

Como pone de manifiesto William Kleb en su interesante ensayo titulado «Marginalia: Streetcar and Foucault» (1993), la excentricidad sexual de Blanche es reprimida por medio del castigo, la disciplina y el control, mecanismos todos ellos que nos remiten a lo descrito por Foucault. Así, Mitch demanda que ella le informe sobre su vida sexual para llegar a la conclusión de que no es «suficientemente limpia», y Stanley la fuerza a

\footnotetext{
${ }^{2}$ El crítico Bert Cardullo (1988) sostiene que esta violación es fruto de la lujuria producida por un consumo incontrolado de alcohol, interpretación con la que estoy en absoluto desacuerdo ya que convierte en conducta patológica lo que es simplemente maldad: Stanley siente con toda frialdad la necesidad de dar a Blanche una lección y, cuando surge la oportunidad de estar a solas con ella, la aprovecha pronunciando su ya famosa frase: «We've had this date with each other from the beginning».

${ }^{3}$ «I have always depended on the kindness of strangers» es la última frase que pronuncia Blanche cuando en la última escena se rinde confiada a los brazos del médico que la lleva hacia su internamiento en el psiquiátrico.
} 
tomar parte en violentos interrogatorios en los que él se erige en único juez, manipula la verdad y se jacta de conocer un oscuro secreto con el que la amenaza y aterroriza. Finalmente, la somete a un extremo castigo físico (violación) a través del cual la obliga a pagar el daño que ella le ha infligido en su imaginario al constituirse en una amenaza para la imagen de macho que él tiene de sí mismo: el ser sexualmente independiente y el haber podido buscar subversivamente la satisfacción de su necesidad fuera de lo establecido socialmente por los hombres. Así, Stanley consigue, a través de la coacción y la manipulación, transmitir a todos los demás su visión de Blanche. Cabría pensar si incluso a ella misma, ya que los espectadores ven cómo su ego se va fragmentando y fragilizando frente a la implacable y controladora observación a la que la somete su cuñado. Como sostiene la crítica Laurilyn J. Harris, Stanley fuerza su interpretación de la realidad sobre ella produciéndole un miedo horrible a que eso sea cierto. Y eso aniquila su razón, escapándose de todo ello por medio de la locura que, yo añadiría, es una forma de muerte social:

[...]Just for that short space of time, she sees herself through his eyes, and perhaps, in her guilt and wretchedness, she also sees the jeering faces of everyone she ever knew shouting [...] I saw! I know! You disgust me! (1993: 96).

Foucault describe la psicopatología como alienación y sostiene que «el beneficio que el enfermo [mental] encuentra en negar su presente, refugiándose en la enfermedad, reside en su necesidad de defenderse de ese presente» (1961: 43), ya que «no se está alienado porque se está enfermo, sino que en la medida en que se está alienado, se está enfermo» (98), al proyectar en uno mismo distintos conflictos y contradicciones sociales. Así pues, Blanche está enferma (entendiéndolo siempre en términos foucauldianos), y se nos presenta como una histérica masiva que desestabiliza el poder establecido y, por ello, sus heridas psíquicas se convierten precisamente, en la fuente de su poder; un poder subversivo que ella misma ignora poseer pero que causa un enorme rencor en Stanley.

La histeria de Blanche (paralela a la propia histeria del autor como al mismo Tennessee Williams le gustaba señalar) es, además de una neurosis, una forma de expresión del inconsciente; algo que desmonta el discurso del amo, ese amo que, según Jacques Lacan, la histérica erige en el Otro-del-saber y al que dirige toda su performance y mascarada, puesto que una de las características de la histeria es precisamente el desear-de manera imposible y constante- un amo sobre el cual reinar.

Blanche, como buena histérica, está obsesionada con la perfección física. Se jacta constantemente de no haber engordado un gramo en diez años, miente sobre su edad al considerarse envejecida a pesar de estar en torno a los treinta, se maquilla de manera recargada incluso en casa, se perfuma y cambia de vestido como en una performance emergiendo del baño al modo de una primadonna que entra en escena desde su camerino, se adorna utilizando joyas y pieles con profusión, se esconde de la luz del día temerosa de mostrar su auténtica edad, coloca filtros de papel en las bombillas para matizar y transformar la realidad, y se erige en una mujer portadora de la feminidad que ella considera normativa en su imaginario. Pero la preocupación de Blanche por su aspecto no proviene de la vanidad ni el narcisismo, sino de la sensación de que su valía se está viniendo abajo; un intento desesperado de crear un yo romántico e idealizado 
frente a la escrutadora y cruel mirada de Stanley que la fragmenta y aniquila ${ }^{4}$ Todo es, como indica el psicoanalista Lucien Israël, una producción teatral, una representación, un juego ante los espectadores; un hacerse ver en un fingimiento que resulta casi cómico. Y añade que la histérica representa ser «la mujer» precisamente porque no está segura de serlo, sino todo lo contrario. Como sin audiencia no hay acto histérico y sin espectadores no existiría ese «hacer como si», ese «semblante», tal como lo denominaba Jacques-Alain Miller, Blanche necesita representar esta paradoja, este «dado a ver» esencial en la histeria, mientras busca una manera de ser mujer, por lo que, inconscientemente, intenta aproximarse a ese modelo de lo que ella cree que es serlo, un modelo basado entre otras cosas en una perfección física sin mancha, algo para su desesperación nunca alcanzado 5 .

La figura de la Blanche histérica surge siempre entre cortinas de humo y el espectador nunca está seguro de nada. Ella nos mantiene constantemente en suspenso al no ser nada nunca lo que parece ser a primera vista y, aunque dice en la segunda escena que no tiene nada que esconder, siempre parece estar ocultando algo: le confiesa a su hermana Stella haber estado muy nerviosa en el interrogatorio sobre la herencia al que la somete Stanley, pero también haber flirteado con él, indiferente a la incomodidad que este comentario, nada trivial, aunque aparentemente inocente, pueda crear en su hermana; se presenta como una Blanche púdica y virginal (de hecho afirma ser del signo zodiacal Virgo), pero descubrimos que arrastra un pasado promiscuo en Laurel; cuando Mitch la acompaña a casa tras una salida juntos manifiesta, con falso recato, dificultades para aceptar sus pequeñas «familiaridades» pero no duda en hacerle pasar al dormitorio a oscuras y a solas a beber una última copa mientras, hablando en francés, dice como quien no quiere la cosa: «Voulez-vous coucher avec moi ce soir?» Su actitud en apariencia extremadamente púdica contrasta con la omnipresencia de su cuerpo desnudo en sus interminables baños tras la puerta cerrada en el piso diminuto, algo de lo que todos son conscientes, dado lo mucho que ella los comenta, dirigiendo así la atención de todos hacia su desnudez en el agua. Blanche es, pues, la encarnación de una sexualidad confusa típicamente histérica que en muchas ocasiones se traduce en frigide $z^{6}$ y falta de deseo sexual tras una apariencia invitadora y excitante. Es la seducción concebida como tabla de salvación, como una muestra de estar viva; una seducción puesta al servicio de la identificación imaginaria fálica más que de desear al otro, como indica el psicoanálisis lacaniano, una maniobra que ignora que, como dice Jean Baudrillard en su libro sobre la seducción, seducir no es ni amar ni desear, sino sólo desafiar el acto sexual al provocar el deseo para decepcionarlo inmediatamente después ${ }^{7}$.

¿Siente Blanche deseo sexual? Probablemente no, atrapada, entre otras cosas, en un pasado del que no hay escape posible. Ante su fracasado matrimonio con Allan Grey, un joven homosexual, Blanche experimenta el devastador dolor de sentirse no deseada, de

\footnotetext{
${ }^{4}$ Laurilyn J. Harris (1993) destaca este importantísimo aspecto del drama de Blanche.

${ }_{5}^{5}$ De hecho, en la quinta escena, Blanche, refiriéndose a Mitch, le confiesa a Stella que quiere «engañarle lo suficiente para conseguir gustarle.»

${ }^{6}$ La frigidez histérica no es impotencia, sino simplemente un «no querer».

${ }^{7}$ En otros casos, la histérica reivindica el goce ante un hombre que no quiere saber nada de él. Así pues, la histeria está hecha de permanente insatisfacción. Una insatisfacción que asegura la existencia del sujeto deseante siempre de algo diferente.
} 
ser un objeto caído para el otro que no resulta ser el Otro-del-deseo para ella. Pero, ¿por qué se casa con un homosexual del cual sólo puede obtener frustración sexual? Todos los psicoanalistas insisten en que si algo caracteriza a la histérica es que su gran deseo es precisamente mantener el deseo insatisfecho para asegurarse así de que éste siga existiendo. Según el psicoanalista Joël Dor:

El histérico se encierra, en efecto, en una lógica psíquica irrebatible: para mantener su deseo, el sujeto se esfuerza en no darle jamás un objeto sustitutivo posible, a fin de que la insatisfacción resultante motorice cada vez más el deseo en esta aspiración hacia el ideal del ser (1991: 95).

La necesidad de amor y felicidad de Blanche se ve brutalmente truncada ante otro (su marido) que se hace, tras su suicidio, permanentemente ausente y que continúa siendo en su imaginario fuente de culpa y dolor: dolor por no haberla deseado; culpa porque ella se responsabiliza de su suicidio. Blanche se acusa a sí misma de haber destruido a Allan y busca en otros, preferiblemente jóvenes como él, una mirada de acogimiento, un lugar donde alojar su ser pulsional y libidinal. La propia Blanche confiesa a Mitch que

[...] intimar con desconocidos era lo único que parecía llenar el vacío de mi corazón... Yo creo que era pánico, sólo pánico, lo que me empujaba de uno a otro. Buscaba protección, en todas partes, en los sitios más... improbables... (Novena escena).

Efectivamente, esta búsqueda la lleva a encontrar en los jóvenes de Laurel la burla cruel, el desprecio y el abuso; el brutal desgarro del desamparo ante un otro que no la aloja, la caída del ser del sujeto ante lo que Lacan denominaba «el grado cero del amor», hecho de la indiferencia que siente el otro ausente. Y ese abandono cruel queda como una pulsión en el vacío que retorna al cuerpo de Blanche en forma de una angustia masiva de la que intenta huir a través de un consumo tóxico de alcohol típicamente histérico, o por medio del traslado físico de lugar, encontrándose en Nueva Orleans, para su desgracia, con lo peor. Pobre Blanche, huyendo de sí misma, buscándose agotada en otros cuerpos en los que intenta mantener su conexión con la vida, midiéndose -como indica Luce Irigaray que le sucede casi siempre a las mujeres- por lo que ella representa en el deseo masculino (1985). No hay pues en ella esa supuesta ninfomanía que algunos críticos han declarado ver $^{8}$, sino necesidad, urgencia de contacto a través de la piel, una reivindicación de sí misma al verse reflejada en otra mirada que la desea y que enciende por un segundo su propio deseo, algo que le genera culpa y rechazo de sí misma ya que Blanche no da cabida en ella ni a lo sensual ni a lo físico. Cayendo en ese contacto físico íntimo que en el fondo rechaza, ofreciéndose como objeto presto casi a ser devorado, Blanche se separa de lo que ella misma cree ser en una típica alienación subjetiva del histérico en relación con el deseo del Otro que es, como destaca Joël Dor, algo que redobla la economía neuróticamente insatisfecha del deseo (1991: 90). La Blanche seductora de chicos sostiene muy asertiva-

\footnotetext{
${ }^{8}$ José Domenech, en su tesis doctoral titulada La soledad en la obra de Tennessee Williams (1991), sostiene que este personaje inicia la serie de ninfómanas en la obra del autor sureño. Muchos otros críticos angloamericanos han considerado a este personaje una prostituta. Mary Ann Corrigan (1997), en cambio, destaca la importancia que tienen para Blanche estos encuentros mediante los que intenta luchar contra la sensación de muerte que arrastra, así como lo que suponen de búsqueda de ternura y reivindicación de su persona.
} 
mente su deseo de serlo, pero no su deseo sexual, que probablemente no exista. Según señala el psicoanalista Juan David Nasio, «no hay más goce que el del cuerpo», pero el cuerpo/deseo histérico de Blanche se vela y se desvela, se muestra y se rehúye, en un juego infinito, misterioso y agotador que desestabiliza el sistema dicotómico de géneros patriarcal, basado tradicionalmente en la dialéctica entre la demanda y la sumisión.

Efectivamente, Blanche, a su manera dolorida y perturbada, verbaliza su necesidad, se resiste a ser excluida por el discurso social dominante y boicotea los estándares patriarcales acerca de lo que se espera de las mujeres. Su manera tentativa de ser mujer ofrece una versión alternativa e insumisa de la feminidad, algo que ni Stanley ni Mitch soportan. Una feminidad, en este caso, de rasgos histéricos, que irrumpe en y altera el discurso del amo, como siempre ha hecho la histeria desde que fuera tipificada a finales del XIX por Charcot. Es dentro de este contexto que podemos considerar esta obra, y en general otras muchas de Tennessee Williams, como muy poco convencional respecto al sexo y al género, ya que parecen alterar, de manera sutil y con una calidad literariadeslumbrante, visiones tradicionales de la masculinidad y la feminidad, la heterosexualidad y la homosexualidad, en boga en aquellos años ${ }^{9}$.

Para autores como Nicholas Pagan, Blanche es un personaje que, a pesar de haberse escapado del marco que establece el deseo masculino (ese deseo que, como sostiene Irigaray, es en el que la mujer se refleja y que en muchos casos es lo que le otorga su identidad), es una doble marginada: marginada como mujer, por el hecho de serlo; como un gay masculino, por buscar chicos jóvenes. Según esta lectura y otras similares, Blanche da la vuelta a la tradición y se convierte en seductora, pero no en seducida, y busca, como si fuera un hombre, jóvenes que la satisfagan. Los que esto defienden sostienen que una lectura de Blanche en clave sólo femenina amputaría otros significados potenciales de este texto mucho más complejos e ignoraría la importancia del sexo y el género en la obra (Pagan, 1993). Dentro de esta línea, interpretaciones travestidas de la obra ${ }^{10}$, como la ya mítica titulada Belle Reprieve, del grupo Split Britches (y su estética lesbiana butch-femme) en colaboración con el grupo británico Bloolips (y su estética drag radical), estrenada en 1991, desconstruyen y renegocian las ya míticas figuras de Blanche y Stanley y, en general, el binarismo estereotipado de género, considerándolo sólo un constructo, con una visión feminista/queer posmoderna basada en un role-playing sexualmente radical que transmite otro nivel de inteligibilidad en esta obra, una lectura «camp» que se basa, como plantea Susan Sontag, en una manera de mirar el mundo como un fenómeno puramente estético, «no en términos de belleza, sino en términos de grado de artificio» (2007:275).

\footnotetext{
${ }^{9}$ Como indica David Savran en Communists, Cowboys and Queers, frente a la masculinidad normativa de la época (que deseaba y degradaba a las mujeres), la que presenta T. Williams no es paternalista, sino volátil y peligrosa; algo cuya «otredad» está erotizada.

${ }^{10}$ David Savran destaca la despreciativa visión que críticos como Edgar Hyman han tenido de lo que ellos llaman la «estrategia Albertina» como maniobra de aproximación de otros teóricos a los textos de T. Williams. El fundamento de dicha estrategia radica en que, basándose en la supuesta homosexualidad del autor, las heroínas eran interpretadas como hombres travestidos en una maniobra transgénero. Hyman deplora esta interpretación, que parece debilitar la viril tradición literaria norteamericana. Frente a tal perspectiva, Savran defiende que este tipo de lectura no sólo da la vuelta, sino que desconstruye el sistema binario de géneros (1992: 115-120).
} 
El trabajo de grupos teatrales como Split Britches surge de la teoría queer postmoderna, que aparece a principios de los años noventa y que constituye sin duda un interesante esfuerzo por reescribir y ampliar el concepto de género. El término queer pretende aunar la(s) sexualidad(es) gay y lesbiana, y en general todas las prácticas sexuales »periféricas», a la vez que defiende el concepto de la »incertidumbre radical» (radical uncertainty). Esta incertidumbre impide acuñar un concepto de identidad estable por miedo a esencializar un sujeto al intentar definirlo, o a homogeneizar las diferencias étnicas o de género bajo un absoluto. Esta tendencia actual se ampara y justifica en teorías postmodernas influidas por Foucault y Derrida. Los juegos de roles lesbianos siguen directamente a Derrida y su afirmación de que no se puede escapar de una oposición binaria -en este caso la masculina/femenina del género-, sino sólo »desestabilizarla». Lo queer es, pues, un trabajo de desterritorialización que afecta tanto al espacio de la heterosexualidad como al espacio de lo corporal y, por tanto, también una resistencia al proceso de llegar a ser «normal». En consecuencia, el lesbianismo postmoderno plantea la incapacidad de eludir el género, pero intenta desvirtuarlo, jugando con sus significados; de ahí la popularidad en nuestros días del travestismo, la pornografía, la mascarada hiperfemenina o hipermasculina o los atuendos concretos utilizados en la iconografía sadomasoquista, tan en boga hoy en el mundo lesbiano.

De todo ello se nutre Belle Reprieve (una versión de Belle Reve, la casa de los ancestros de Blanche y Stella), que indica, literalmente, un alto en el camino, un descanso liberador que nos permite escapar por un divertido rato de las versiones coercitivas de la feminidad y masculinidad vigentes mediante la extravaganza y la crítica.

Bloolips es una troupe formada por los transformistas Bette Bourne y Paul Shaw, más conocido como «Precious Pearl», y la Split Britches Company está compuesta, entre otras, por la pareja de lesbianas (también pareja en la vida real) Peggy Shaw y Lois Weaver. Así, en Belle Reprieve una lesbiana butch muy fornida (Peggy Shaw) representa a Stanley; el actor transformista Bette Bourne es Blanche; Lois Weaver es Stella, y Precious Pearl, una conocida drag queen, actúa como hombre heterosexual (Mitch) por lo que las parejas pueden ser leídas como heterosexuales y homosexuales a la vez (Solomon, 1997:158). Stella y Mitch representan versiones menos exageradas de la feminidad y la masculinidad, pero que resultan ser, igual que las de Blanche y Stanley, sólo provisionales y, en general, todo en torno al género se plantea en esta representación como ilusorio, como una mascarada confusa en la que dicho concepto se halla entrecomillado. Efectivamente, Stanley y Blanche, la pareja teóricamente heterosexual, está conformada por una lesbiana butch y Bette Bourne, un transformista, imitando la estética lesbiana butch-femme, mientras que Precious Pearl confesó en repetidas ocasiones sentirse mucho más artificial representando al heterosexual Mitch que cuando actúa con su extravagante maquillaje y sus elaboradas pelucas para Bloolips ${ }^{11}$. Cuando Peggy/Stanley hurga en el baúl de Blanche y va sacando sus cosas para controlar qué lleva, se va colgando del cuello con una percha sus vestidos, se pone sus diademas, sus guantes y sus tacones hasta

\footnotetext{
${ }^{11}$ Del mismo modo, Peggy Shaw ha comentado en diversas ocasiones que en el original de Williams el odio hacia las mujeres de Stanley es tan marcado, su afecto hacia los hombres tan claro, y su manera de presentarse tan de Mae West, que todo ello le constituye como «obviously a faggot». Véase: http://web.missouri.edu/ benderr/courses/370/sessions/39.html.
} 
transformarse de drag-king lesbiano butch en drag-queen: una mujer vestida de hombre que representa a un hombre que a su vez se disfraza de mujer. Lo camp-lesbiano como representación de una hiperfeminidad y una hipermasculinidad que se convierten en formas nuevas de enunciación por exceso. La identidad de género constituida en un acto performativo e inestable, una performance desestabilizadora del significante-amo imperante construida sobre cuerpos carnavalescos. Algo puramente ilusorio y en permanente estado de transformación. Y esta representación queer, lejos de ser una banalidad, se convierte en una demoledora crítica cargada de connotaciones políticas que cuestiona los roles de género, a la vez que explora y rechaza el realismo que tanto ha oprimido el formato teatral al reclamar la magia y la sorpresa inherentes a la experimentación escénica.

Si, como decía Joan Rivière, toda feminidad es mascarada y un hacer-como-si; y si, como decía Lacan, en muchos casos la mascarada femenina sirve para que la mujer se coloque en lugar del objeto del fantasma del hombre y atraerlo, en un puro narcisismo del deseo, un deseo del deseo del Otro (algo que parece estructural en la mujer), entonces tanto la performance histérica de la Blanche más ortodoxamente leída en la obra de Tennessee Williams (en la que la imagen que se proyecta y lo que se cree ser son coincidentes, ya que, como ella misma reconoce en la segunda escena, «el atractivo de una mujer tiene un cincuenta por ciento de fingimiento, de ilusión»), como la hiperfemenina extravaganza llevada más allá del límite del discurso representada por Bette Bourne en Belle Reprieve convergen: ambas son una búsqueda, un permanente cuestionamiento de qué es ser una mujer; y es que decirse hombre o decirse mujer, reconocerse como sujeto sexuado, como Lacan expone en el seminario «Aún», es un posicionamiento en lo simbólico y, por tanto, no cifrado en la anatomía. La anatomía ya no es destino y para todos, como para Blanche, aun sin rumbo prefijado, en nuestra travesía de seres hablantes, la geografía es siempre la del deseo. Un deseo que Tennessee Williams, adelantándose unos años a lo que más tarde formularía Lacan, enunció en boca de una lúcida Blanche como lo contrario a la muerte; un deseo que, aun cuando parezca detenerse unos minutos para luego alejarse como el tranvía que da título a la obra, no da jamás su brazo a torcer.

Bibliografía

BAUdrillard, Jean (1981). De la seducción. Trad. Elena Benarroch. Madrid: Cátedra.

CARDUllo, Bert (1988). «Drama of Intimacy and Tragedy of Incomprehension: A Streetcar Named Desire Revisited», en Modern Critical Interpretations: Tennessee Williams's A Streetcar Named Desire. Ed. Harold Bloom. Nueva York: Chelsea House. 79-92.

CASE, Sue Ellen (1996). Split Britches: Lesbian Practice/Feminist Performance. Londres y Nueva York: Routledge.

Corrigan, Mary Ann (1997). «Realism and Theatricalism in A Streetcar Named Desire», en Critical Essays on Tennessee Williams. Ed. Robert A. Martin. Nueva York: G. K. Hall \& Co. 8393.

Domenech, José (1991). La soledad en la obra de Tennessee Williams. Tesis doctoral. Madrid: U. Complutense. 
DoR, Joël (1991). Estructuras clínicas y psicoanálisis. Trad. Víctor Goldstein. Buenos Aires: Amorrortu.

FouCAult, Michel (1961). Enfermedad mental y personalidad. Trad. Emma Kestelboim. Buenos Aires: Paidós.

GibBs, Wolcott (1996). «Two Views of the South», en The Critical Response to Tennessee Williams. Ed. George W. Crandell. Londres: Greenwood Press. 56-58.

HARRIS, Laurilyn J. (1993). «Perceptual Conflict and the Perversion of Creativity in A Streetcar Named Desire», en Confronting Tennessee Williams's A Streetcar Named Desire. Essays in Critical Pluralism. Ed. Philip C. Kolin. Londres: Greenwood Press. 84-103.

IRIGARAY, Luce (1985). This Sex which Is Not One. Ithaca: Cornell U.P.

ISRAËL, Lucien (1979). La histeria, el sexo y el médico. Trad. Aurelio López Zea. Barcelona: TorayMasson.

KLEB, William (1993). «Marginalia: Streetcar and Foucault», en Confronting Tennessee Williams's A Streetcar Named Desire. Essays in Critical Pluralism. Ed. Philip C. Kolin. Londres: Greenwood Press. 27-43.

NAsio, Juan David (1993). Cinco lecciones sobre la teoría de Jacques Lacan. Trad. Graciela Klein. Barcelona: Gedisa.

PAGAN, Nicholas (1993). Rethinking Literary Biography. A Postmodern Approach to Tennessee Williams. Londres: Associated University Presses.

Savran, David (1992). Communists, Cowboys and Queers. The Politics of Masculinity in the Work of Arthur Miller and Tennessee Williams. Minneapolis: U. of Minnesota P.

Solomon, Alisa (1997). Re-Dressing the Canon: Essays on Theatre and Gender. Nueva York: Routledge.

SonTAG, Susan (2007). Contra la interpretación. Trads. M. Pesarrodona y H. Vázquez. Barcelona: Debolsillo.

WiLliams, Tennessee (2007). El zoo de cristal/Un tranvía llamado deseo. Trad. Amado Diéguez. Barcelona: Alba Editorial. 